\title{
Safety pharmacology and subchronic toxicity of jinqing granules in rats
}

\author{
Xuerong Zhou ${ }^{\dagger}$, Qian Rong ${ }^{\dagger}$, Min Xu, Yuanli Zhang, Qi Dong, Yuanling Xiao, Qiji Liu, Helin Chen, Xiaoyu Yang, \\ Kaisheng Yu, Yinglun Li* ${ }^{*}$, Ling Zhao, Gang Ye, Fei Shi and Cheng LV
}

\begin{abstract}
Background: Jinging granules which are made of a mixture extract that contains Radix Tinosporae and Canarii fructus in proportions according to a longstanding formula have a good effect on the prevention and treatment of gastric ulcer disease. It has not been through safety through systematic toxicological studies, however. To provide basis for clinical application, we performed safety pharmacology and subchronic toxicity experiments in specific pathogen-free Sprague-Dawley rats.
\end{abstract}

Results: In safety pharmacology experiments, Jinqing granules had no evident adverse effects on the central nervous, cardiovascular, or respiratory systems. In subchronic toxicity study, 2-8 g/kg of Jinqing granules induced no evident adverse effects on Clinical signs, body weight changes, food and water intake, death daily, indicators of urine, hematological assay, serum biochemistry, organ coefficient and histopathological examination. However, the $16 \mathrm{~g} / \mathrm{kg}$ dose was associated with slightly slowed weight growth, decreased number of sperm in seminiferous tubules and increased values of serum aspartate aminotransferase and bilirubin. During the 30-day feeding test, 3 rats that received the $16 \mathrm{~g} / \mathrm{kg}$ dose died, but the deaths were most likely due to trauma of oral gavage, not to drug toxicity.

Conclusion: Jinqing granules given to Sprague-Dawley rats orally for 30 days at a dose of $8 \mathrm{~g} / \mathrm{kg}$ or less appears safe, but higher doses were not proven safe. The significance of these observations with respect to animal usage of Jinqing granules deserves thorough investigation.

Keywords: Jinqing granules, Rats, Toxicity, Safety pharmacology, Subchronic toxicity

\section{Background}

China has a several-thousand year history of using traditional medicines in clinical practice. The invention and application of traditional Chinese medications, based on specific theoretical systems and patterns of use, reflect the characteristics of Chinese culture, with its long history and rich natural resources [1]. So far, there are about 12,000 kinds of Chinese traditional medicine used in clinical, mostly herbs implied [2]. The origins and development of Chinese medicine are life's practical experiences and medical practices of laboring people [3]. The World Health Organization [4] has reported that about $80 \%$ of the world's populations, especially people who live in developing countries, use natural medicines to treat disease. In recent years, with rapid global economic integration,

\footnotetext{
* Correspondence: liyinglun01@163.com

${ }^{\dagger}$ Equal contributors

College of Veterinary Medicine, Sichuan Agricultural University, Chengdu, Sichuan 611130, People's Republic of China
}

China's pharmaceutical industry has moved strongly into the international medicine market [5]. However, the safety and effectiveness of many common Chinese traditional herbs have not been established [6, 7]. Therefore, in order to ensure the safety of prescribed traditional Chinese medicine, it is necessary that they undergo subchronic toxicity and pharmacological safety testing.

Radix Tinosporae is the root of Tinospora sagittata (Oliv.) Gagnep, or Tcapillipes Gagnep [8]. Radix Tinosporae is used for treating sore throat, carbuncle, furuncle, diarrhea, abdominal pain and other conditions [9-12]. Canarii fructus, the dry ripe fruit of Canarium album Raeusch, is used in the treatment of sore throat, cough and sputum viscosity [13].

Jinqing granules are made of a traditional Chinese medicine mixture extract that contains Radix Tinosporae and Canarii fructus in proportions according to a longstanding formula [14]. Jinqing granules were used in our application for a drug patent in 2014. In early trials, 
Radix Tinosporae was effective in the prevention and early treatment of helicobacter pylori [15]. The main active constituents of the granules are gallic acid and tetrahydropalmatine. According to literature reports on traditional Chinese medicines, Canarium ablbum Raeusch and Tinospora capillipes Ganep have favorable effects on gastric abscesses, diarrhea, and abdominal pain [8]. Even though Jinqing granules are used to treat a variety of diseases, their safety in long-term use is still questionable. About $10 \%$ of the world's population has gastric ulcers, and about $1 \%$ of the ulcers progress to gastric cancer [16]. Therefore, Jinqing granules may have a very large market.

In early acute toxicity experiments, we found that the lethal dose $50\left(\mathrm{LD}_{50}\right)$ of Jinqing granules is $5 \mathrm{~g} / \mathrm{kg}$ in rats. On the basis of the $\mathrm{LD}_{50}$, in this work, we have studied subchronic toxicity of Jinqing granules given orally to Sprague-Dawley (SD) rats in accordance with relevant Chinese standards.

\section{Methods}

\section{Jinqing granules}

Radix Tinosporae and Canarii fructus were both collected from Chengdu (Sichuan, China). The plants were identified and authenticated by Professor Qiao-jia Fan of the College of Veterinary Medicine, Sichuan Agricultural University, Chengdu, China. The mixture extract that contains Radix Tinosporae and Canarii fructus in proportions according to a longstanding formula add some excipients to make Jinqing granules. The granules were completely dissolved in sterilized distilled water and made into dosages of $16 \mathrm{~g} / \mathrm{mL}, 8 \mathrm{~g} / \mathrm{mL}, 4 \mathrm{~g} / \mathrm{mL}$, and $2 \mathrm{~g} / \mathrm{mL}$, according to the requirements of China's newdrug safety evaluation.

\section{Animals}

Healthy male and female SD rats, 4 and 8 weeks old, were purchased from the specific pathogen-free facility at Chengdu Dossy Experimental Animals Co., Ltd. [License no. SCXK (Sichuan) 2008-24]. All experimental procedures involving animals were approved by Sichuan Agricultural University Animal Care and Use Committee (registration No. SCAU2016061801). Based on the principles of the International Committee on Laboratory Animals, the rats were separated equally according to gender and maintained at $20-25{ }^{\circ} \mathrm{C}$ and relative humidity of $55 \pm 5 \%$. Artificial lighting was adjusted to $12 \mathrm{~h}$ of light (from 08:00 to 20:00) and $12 \mathrm{~h}$ of darkness from 20:00 to 08:00. Conventional laboratory feed was provided by the Chengdu Dashuo Biology Science and Technology Co., Ltd. The rats were allowed to drink water freely, and they acclimated for 7 days before experiments were begun.

\section{Safety pharmacology experiments}

Safety pharmacology experiments were performed according to guidelines of the Veterinary Drugs Control [17-20].

Fifty SD rats were randomly distributed into 5 groups (5 female and 5 male in each group). The five groups were: Group I, normal control group (sterile distilled water); Group II, 2 g/kg Jinqing granules; Group III, $4 \mathrm{~g} /$ kg Jinqing granules; Group IV, 8 g/kg Jinqing granules; and Group V, $16 \mathrm{~g} / \mathrm{kg}$ Jinging granules. Animals were treated daily at 9 a.m. with gastric infusion in a volume of $10 \mathrm{ml} / \mathrm{kg}$ given for 7 days.

We observed the animals for behavior, posture, salivation, pupil change, muscle tremors, hair, and feces were observed from 10 a.m. to 16 p.m. continually for 14 days [17-20]. In order to prevent living animals from eating animals that had died due to accumulation of drug in the body, endangered or dead rats were autopsied promptly [21].

Before and $24 \mathrm{~h}$ after the last administration of control water or Jinqing granules, the rats were placed in the versatile recorder of rats' locomotor activity and allowed to adapt to the environment for $30 \mathrm{~min}$. Their activity (number of movements in $1 \mathrm{~min}$ ) was recorded by watching the rats' movements in order to determine if this aspect of the central nervous system was normal.

The climbing pole test was performed in order to evaluate the mobility of the rats after receiving the medication for various times. Twenty-four hours after the last administration, a smooth metal bar was erected vertically and fixed at the bottom. The rats were placed at the top of the metal bar and allowed to descend head first. Their ability to coordinate this activity was graded as: Level 0, normal step-by-step climbing down; Level 1, coasting down; Level 2, inability to hang from the lever; Level 3, discoordination over a period of time.

On the day before medication was given, the day after it was given, and the eighth day after being given, $3 \%$ pentobarbital sodium was injected intraperitoneally to anesthetize the rats [17-20]. The animals' heart rate, electrocardiogram, and the depth of breathing and respiratory rate were recorded with the BL-420F multi-channel physiological signal acquisition processing system.

\section{Subchronic toxicity experiment}

The toxicity experiments were conducted according to the Economic Cooperation and Development Guideline 407 [22].

One hundred-twenty rats were randomly distributed into 6 groups (10 female and 10 male rats in each group). The 6 groups were: Group I, normal group; Group II, saline control group; Group III, $2 \mathrm{~g} / \mathrm{kg}$; Group IV, $4 \mathrm{~g} / \mathrm{kg}$; Group V, $8 \mathrm{~g} / \mathrm{kg}$; Group VI, $16 \mathrm{~g} / \mathrm{kg}$ in a volume of $10 \mathrm{ml} /$ $\mathrm{kg}$ Jinging granules. Animals were treated daily at 9 a.m. with gastric infusion in a volume of $10 \mathrm{ml} / \mathrm{kg}$ given for 30 days. The determination of repeated dose 30-day oral 
toxicity was carried out according to the Organization for Economic Cooperation and Development Guideline 407 [22]. In order to avoid accumulation of drug that existed in the dead rats in the living body by eating, and analyzed the causes of death in rats, the dead rats were needed to anatomical analysis immediately. [21].

Daily from 10 a.m. to 16 p.m., we observed the rats' behavior, attitude, presence of saliva, pupillary change, muscle tremors, hair texture, food intake, water intake, feces, poisoning, and death, continually for 30 days. Weight was recorded every three days.

At the end of medication period, urine samples were collected from all animals. The samples were sent to Chengdu Lilai Biology Science and Technology Co., Ltd., for determination of $\mathrm{pH}$, ascorbic acid, specific gravity, glucose, leukocyte counts, nitrite, protein, ketones, urobilinogen, and bilirubin.

About $2.0 \mathrm{~mL}$ of blood was collected in an anticoagulation tube containing sodium citrate to measured hematologic indices, and another $2.0 \mathrm{~mL}$ blood was collected in non-heparinized tubes to measured serum biochemistry.

Rats were sacrificed after blood was collected and were opened surgically for evaluation of possible pathological changes. The weights of liver, heart, spleen, lung, kidney, brain, ovaries, and testes were recorded. The relative weight of organs was calculated according to the formula: organ coefficient $=$ organ weight $/$ body weight $\times 100 \%)[23,24]$.

Organs were soaked in $10 \%$ solution of buffered formalin ( $\mathrm{pH}$ 7.4) for three days, followed by dehydration, embedding, sectioning, dewaxing, and staining with hematoxylin-eosin. Pathologic alterations were assessed with a Nikon 80i optical microscope. Photomicrographs were taken for reference.

\section{Statistical analysis}

Results were analyzed with SPSS 19.0 statistical software. The mean and standard deviation were expressed. One-
Table 1 Jinqing granules effect on autonomic activities in rats $(n=10)$

\begin{tabular}{llll}
\hline Jinqing dose & Gender & Before dosing (times) & After dosing (times) \\
\hline Control group & Male & $160.00 \pm 23.97$ & $183.00 \pm 11.18$ \\
& Female & $175.00 \pm 20.49$ & $161.43 \pm 17.82$ \\
$2 \mathrm{~g} / \mathrm{kg}$ & Male & $153.00 \pm 12.75$ & $138.00 \pm 52.99$ \\
& Female & $168.00 \pm 12.55$ & $182.00 \pm 27.29$ \\
$4 \mathrm{~g} / \mathrm{kg}$ & Male & $145.00 \pm 55.69$ & $125.00 \pm 63.54$ \\
& Female & $161.00 \pm 9.62$ & $135.00 \pm 33.73$ \\
$8 \mathrm{~g} / \mathrm{kg}$ & Male & $179.00 \pm 28.95$ & $167.00 \pm 54.04$ \\
& Female & $156.00 \pm 11.40$ & $136.00 \pm 23.82$ \\
$16 \mathrm{~g} / \mathrm{kg}$ & Male & $170.00 \pm 14.72$ & $155.00 \pm 39.37$ \\
& Female & $178.75 \pm 59.35$ & $176.25 \pm 14.36$ \\
\hline
\end{tabular}

Values represent means $\pm \mathrm{SD}(N=10)$. $P$ values for all comparisons of before dosing and after dosing were $\geq 0.05$.

way analysis of variance (ANOVA) and Newman-Keuls post hoc test were performed for statistical analyses. Statistically significant difference was defined as $p<0.05$.

\section{Results}

\section{Safety pharmacology experiments}

During the safety pharmacology experiments, no deaths occurred, and among all animals in all groups, no abnormalities in fur, posture, pupils, feces, salivation, or muscle tremors were noted. Each dose-group of rats was no evident abnormalities of behavior controlled by the central nervous system, e.g., posture, change in pupil size, salivation, gait, and muscle tremors.

The index for active movement in each dose group of animals receiving Jinqing granules revealed no differences from the index of the control group $(P>0.05)$. Thus, Jinqing granules had no evident effect on the rats' spontaneous activity. The results are shown in Table 1.

In the climbing pole test, the treatment groups and the control-group rats both climbed down step-by-step,

Table 2 The effects of Jinqing granules on the heart rate of rats $(n=10)$

\begin{tabular}{lllll}
\hline Jinqing dose & Gender & Before dosing & The second day after dosing & One week after dosing \\
\hline Control group & Male & $333.60 \pm 25.96$ & $372.40 \pm 27.17$ & $397.00 \pm 36.92$ \\
& Female & $387.60 \pm 10.21$ & $358.80 \pm 70.38$ & $406.40 \pm 12.90$ \\
$2 \mathrm{~g} / \mathrm{kg}$ & Male & $328.20 \pm 23.30$ & $369.40 \pm 48.82$ & $396.20 \pm 10.64$ \\
& Female & $392.20 \pm 9.39$ & $420.40 \pm 25.31$ & $342.60 \pm 24.33$ \\
$4 \mathrm{~g} / \mathrm{kg}$ & Male & $330.20 \pm 28.96$ & $336.40 \pm 38.40$ & $369.20 \pm 57.80$ \\
& Female & $389.20 \pm 11.61$ & $324.00 \pm 16.55$ & $382.20 \pm 49.47$ \\
$8 \mathrm{~g} / \mathrm{kg}$ & Male & $333.60 \pm 25.96$ & $308.60 \pm 35.81$ & $388.60 \pm 35.41$ \\
& Female & $387.60 \pm 10.21$ & $341.60 \pm 48.69$ & $362.00 \pm 41.41$ \\
$16 \mathrm{~g} / \mathrm{kg}$ & Male & $334.50 \pm 21.89$ & $371.25 \pm 27.37$ & $388.50 \pm 13.96$ \\
& Female & $372.25 \pm 10.84$ & $403.25 \pm 74.22$ & $367.25 \pm 34.88$
\end{tabular}

Values represent means $\pm \mathrm{SD}(N=10) . P$ values for all comparisons of before dosing and after dosing were $\geq 0.05$ 
Table 3 The effects of Jinqing granules on the respiratory rate of rats $(n=10)$

\begin{tabular}{|c|c|c|c|c|}
\hline Jinqing dose & Gender & Before dosing & The second day after dosing & One week after dosing \\
\hline \multirow[t]{2}{*}{ Control group } & Male & $96.00 \pm 11.22$ & $81.20 \pm 11.63$ & $91.80 \pm 14.17$ \\
\hline & Female & $88.80 \pm 12.30$ & $94.20 \pm 23.88$ & $105.80 \pm 29.45$ \\
\hline \multirow[t]{2}{*}{$2 \mathrm{~g} / \mathrm{kg}$} & Male & $96.00 \pm 14.70$ & $86.40 \pm 13.89$ & $93.80 \pm 6.94$ \\
\hline & Female & $92.40 \pm 15.06$ & $80.00 \pm 17.39$ & $113.80 \pm 5.76$ \\
\hline \multirow[t]{2}{*}{$4 \mathrm{~g} / \mathrm{kg}$} & Male & $96.80 \pm 12.30$ & $77.00 \pm 9.43$ & $84.80 \pm 7.60$ \\
\hline & Female & $94.25 \pm 13.01$ & $74.40 \pm 10.55$ & $97.60 \pm 17.42$ \\
\hline \multirow[t]{2}{*}{$8 \mathrm{~g} / \mathrm{kg}$} & Male & $91.20 \pm 9.86$ & $70.80 \pm 9.18$ & $94.20 \pm 15.06$ \\
\hline & Female & $88.80 \pm 12.30$ & $68.20 \pm 22.65$ & $98.60 \pm 15.55$ \\
\hline \multirow[t]{2}{*}{$16 \mathrm{~g} / \mathrm{kg}$} & Male & $96.00 \pm 11.22$ & $71.59 \pm 13.30$ & $80.00 \pm 7.48$ \\
\hline & Female & $95.34 \pm 14.70$ & $87.75 \pm 4.5$ & $112.25 \pm 22.40$ \\
\hline
\end{tabular}

Values represent means \pm SD $(N=10)$. $P$ values for all comparisons of before dosing and after dosing were $\geq 0.05$

i.e., at level 0 , which is evidence that Jinqing granules had no discernable effect on the animals' coordination.

The measurements of heart rate and respiratory rate on the day before administration of the medication, the day after administration, and the eighth day after administration revealed no significant differences between control-group rats and those who received Jinqing granules at any dose $(P>0.05)$. At the same time, at three different time points within the same group, there were no significant differences in heart rate and respiratory rate $(P>0.05)$. Thus, we conclude that Jinqing granules had no discernable significant effects on the cardiovascular and respiratory systems of the SD rats. The results are listed in Tables 2 and 3. Figure 1 illustrates timebreath curves of Jinqing granules' effect on the rats and Fig. 2 is time-heart curves.

\section{Subchronic toxicity experiments}

During the 30-day feeding test, 2 male and 1 female rats in Group VI died. Autopsy of these animals disclosed findings suggestive of improper oral lavage administration; no signs of Jinqing toxicity were found. Also, among the various groups of animals, no abnormalities were seen in fur, action, posture, pupillary change, diet, salivation, muscle tremors, and feces.

The rats' food and water consumption are shown in Table 4. Water consumption was not significantly different between groups that received Jinqing granules and those in the control group $(P>0.05)$. Food intake also was similar in the groups that received Jinqing granules and the control group, except that animals, both male and female, that had received $16 \mathrm{~g} / \mathrm{kg}$ (Group VI) consumed slightly less food $(P<0.05)$.

Figure 3 illustrates the weight gain curves of the various groups of male rats, and Fig. 4 is female rats. No difference was recorded between the control group (Group I) and the saline group (Group II) $(P>0.05)$. The body weight gain of Groups III -V (2 g/ $\mathrm{kg}$ to $8 \mathrm{~g} / \mathrm{kg}$ Jinqing granules) also were not significantly different from the body weight gain of control animals $(P>0.05)$. However,
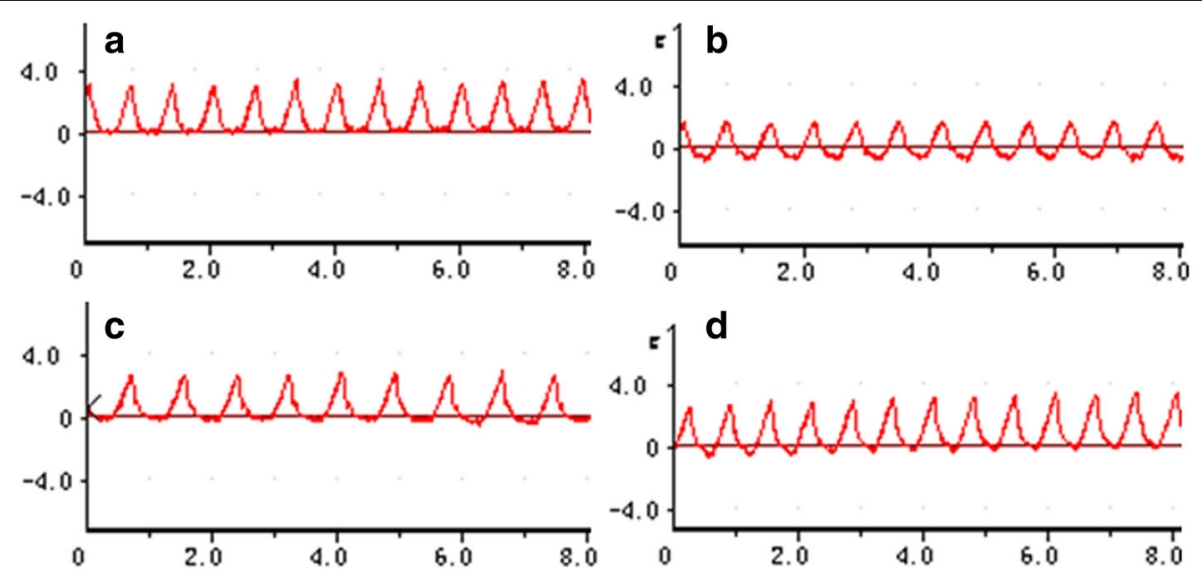

Fig. 1 The effect of Jinqing granules on breath rate of rats. a Control group; b The Group $V$ before administration; $\mathbf{c}$ The Group $V$ at the end of the second administration; $\mathbf{d}$ The Group $\vee$ at a week after the last administration 

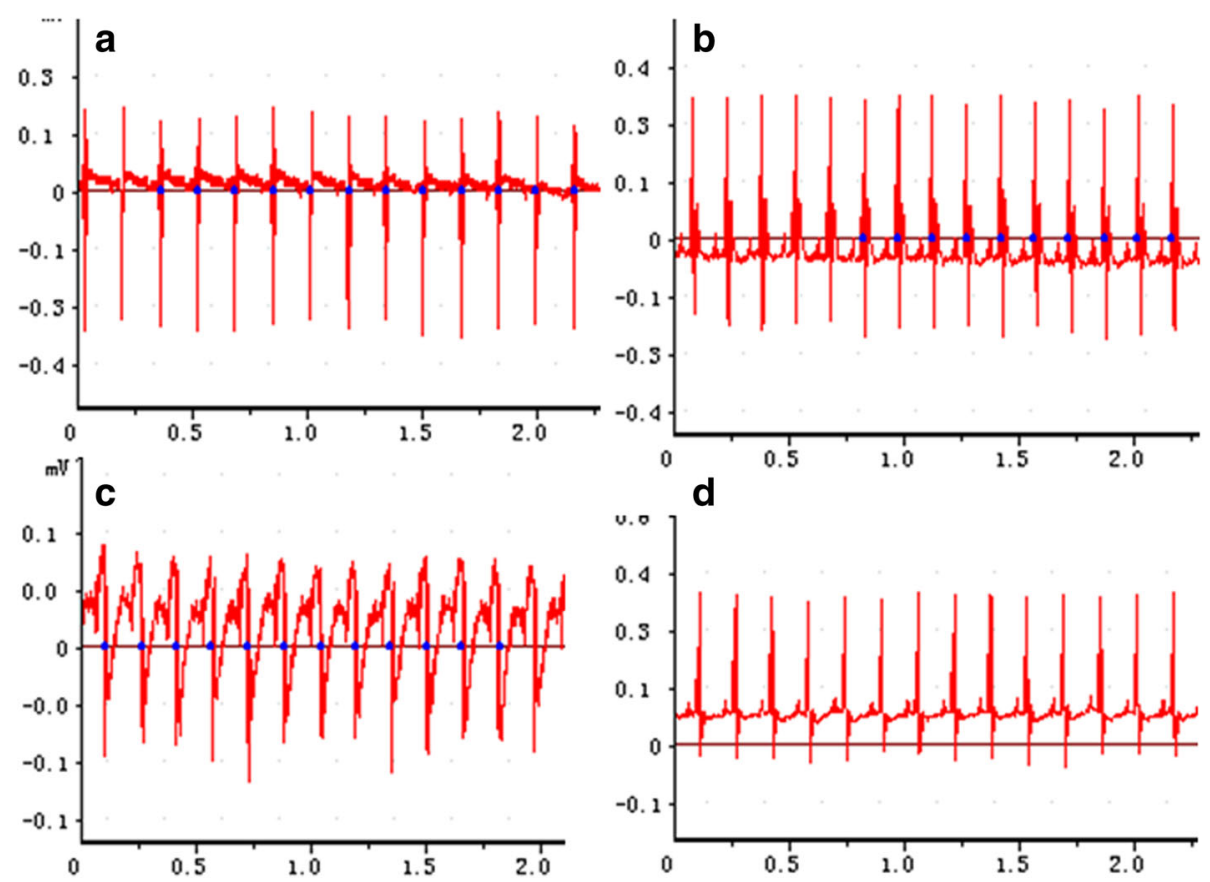

Fig. 2 The effect of Jinqing granules on heart rate of rats. a Control group; $\mathbf{b}$ The Group V before administration; c The Group $V$ at the end of the second administration; $\mathbf{d}$ The Group $\vee$ at a week after the last administration

the weight gain of Group VI $(16 \mathrm{~g} / \mathrm{kg})$ male rats compared with weight gain of control rats was slightly less. Group VI female rats had a similar decline in weight gain, from the 19th to the 31st day.

Indicators of urine samples that, the ascorbic acid in the negative rate is up to $90 \%$. Therefore, other indicators of false negative rate can be ignored. The values for $\mathrm{pH}$, specific gravity, glucose, white blood cells, and nitrite were normal in all animals at all doses of Jinqing granules. The values for bilirubin was slightly increased in the $16 \mathrm{~g} / \mathrm{kg}$

Table 4 Mean food and water consumption of Sprague-Dawley rats orally administered Jinqing granules for 30 days $(n=20)$

\begin{tabular}{llll}
\hline Jinqing dose & Gender & Diet (g/rat/day) & Water (ml/rat/day) \\
\hline Control group & Male & 20.5 & 31.7 \\
& Female & 20.1 & 31.4 \\
Saline group & Male & 21.0 & 31.6 \\
& Female & 20.7 & 31.8 \\
$2 \mathrm{~g} / \mathrm{kg}$ & Male & 20.3 & 31.3 \\
& Female & 20.2 & 31.0 \\
$4 \mathrm{~g} / \mathrm{kg}$ & Male & 20.1 & 30.9 \\
& Female & 19.8 & 31.5 \\
$8 \mathrm{~g} / \mathrm{kg}$ & Male & 19.5 & 31.2 \\
& Female & 19.4 & 30.6 \\
$16 \mathrm{~g} / \mathrm{kg}$ & Male & $17.6^{*}$ & 30.7 \\
& Female & $17.3^{*}$ & 30.3 \\
\hline
\end{tabular}

${ }^{*} P<0.05$ significant difference from control dose compared to control values $(p<0.05)$. The values of occult blood, protein, ketone, and urobilinogen were slightly increased but did not reach statistical significance $(P>0.05)$. Dataes is in Table 5.

Table 6 presents the hematologic indices in the various groups of rats. The indices were not significantly different from control values at any dose of Jinqing granules, except for a slightly higher lymphocyte count at the $16 \mathrm{~g} / \mathrm{kg}$ dose. Although some values in Groups III - VI were higher than in the control group, the differences were not statistically significant.

Serum biochemistry values of treated animals and controls are presented in Table 7. The only statistically significant differences in values between animals that received Jinqing granules and control animals was an increase in aspartate aminotransferase and total bilirubin at the $16 \mathrm{~g} / \mathrm{kg}$ dose $(P<0.05)$.

Organ coefficients are presented in Table 8 . Slightly higher values in the liver and ovaries of animals treated with $16 \mathrm{~g} / \mathrm{kg}$ of Jinqing granules than in control animals were recorded $(p<0.05)$. Otherwise, no differences among the groups were found.

After the 30-day trial, the heart, liver, spleen, lung, kidney, stomach, intestines, brain, testis and ovary were taken from 3 rats of each group for histopathologic examination (Fig. 5). Tissue damage was seen only in animals that had received the $16 \mathrm{~g} / \mathrm{kg}$ dose of Jinqing granules. In the heart, each group had a complete tegument and ventricular and ventricular muscle contour (Fig 5a), 


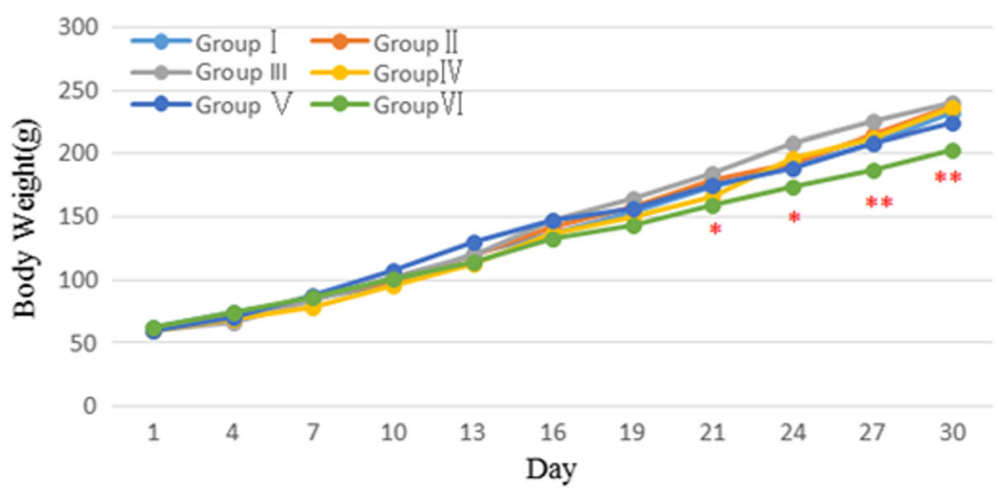

Fig. 3 Body weight changes of male rats during the sub-chronic toxicity study. Data are presented as the mean \pm SD ( 5 rats/sex/group); ${ }^{*} p<0.05$, ${ }^{* *} p<0.01$ Group VI vs. the Group I

with no evident pathological damage. In the liver, compared with the control group (Fig 5b), Group VI animals had expansion of liver sinusoids (Fig $5 \mathrm{c}$ ), and various degrees of vacuolar degeneration in hepatocytes (Fig 5d). In the spleen, in control animals (Group I), the capsule was intact, the boundary between white pulp and red pulp was distinct, and the lymphocyte number was normal (Fig 5e). In contrast, in Group VI rats, the lymphocyte were decreased, and the number of macrophages was increased (Fig 5f). In the lung, the capsules of all groups were complete, and all levels of bronchi (primary bronchus, secondary bronchi, and tertiary bronchi) were neatly arranged in all animals (Fig $5 \mathrm{~g}$ ). In the kidney, pathological changes were not evident in any group. The renal capsule was intact; the boundary between cortex and medulla was clear; and the renal tubules and collecting ducts were arranged neatly, with normal density (Fig 5 h). In the stomach, in Group I to Group VI, structural integrity of the simple columnar epithelium, muscularis mucosa and muscularis propria were maintained (Fig 5i). In the intestines, the mucosa, submucosa, muscular layer, and outer membrane layer structure were intact, and boundaries between these structures were distinct in all animal groups (Fig 5j). In brain, the nerve fiber layer, cerebral cortex, and hippocampus pyramidal cells were arranged neatly and tightly, without inflammatory infiltration or hemorrhagic foci (Fig 5k). In the ovary, from Group I to Group VI, the morphology and quantity of ovarian primordial follicles, proliferating follicles and mature follicles were normal compared with those features in the control animals (Fig 5l). In the testes, seminiferous tubules had a complete structure, and the spermatogenic cells resting in testicular tubules were arranged neatly and tightly (Fig 5m); however, compared with the control group, the number of sperm in seminiferous tubules appeared decreased in Group VI animals (Fig 5n).

\section{Discussion}

In this work, we conducted subchronic toxicity tests [20] and safety pharmacology experiments [17-20] in rats treated with Jinqing granules in order to assess the potential toxicity of this traditional Chinese medicine. Conventional laboratory food was chosen in order to

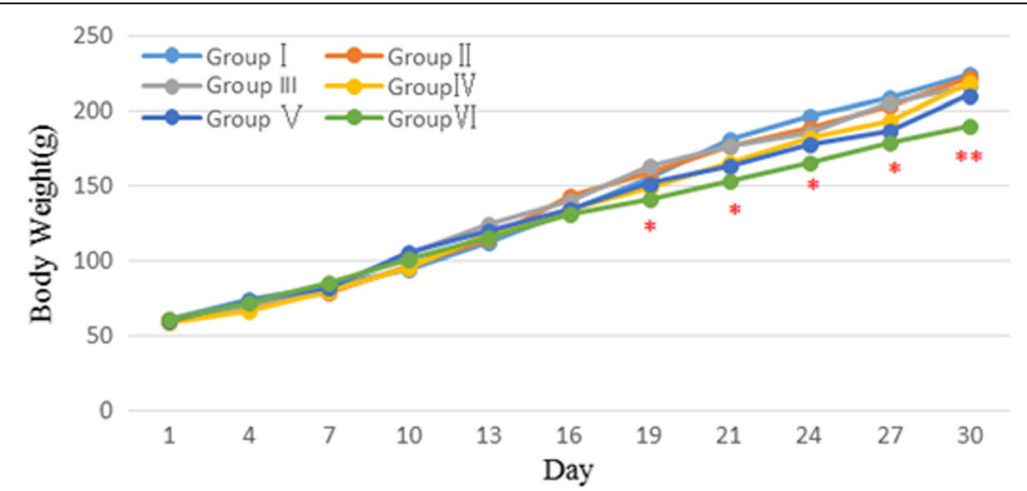

Fig. 4 Body weight changes of female rats during the sub-chronic toxicity study. Data are presented as the mean \pm SD $(5 \mathrm{rats} / \mathrm{sex} / \mathrm{group}) ;{ }^{*} p<0.05$, ** $p<0.01$ Group VI vs. the Group I 
Table 5 Effect of Jinqing granules on indicators of urine in rats $(n=20)$

\begin{tabular}{|c|c|c|c|c|c|c|c|c|c|c|c|c|}
\hline \multirow[t]{2}{*}{ Parameters } & \multicolumn{4}{|c|}{ GLU\% } & \multicolumn{4}{|c|}{ WBC\% } & \multicolumn{4}{|c|}{ NIT\% } \\
\hline & $(-)$ & $(+)$ & $(++)$ & $(+++)$ & $(-)$ & $(+)$ & $(++)$ & $(+++)$ & $(-)$ & $(+)$ & $(++)$ & $(+++)$ \\
\hline Control group & 100 & & & & 100 & & & & 100 & & & \\
\hline Saline group & 100 & & & & 100 & & & & 100 & & & \\
\hline $2 \mathrm{~g} / \mathrm{kg}$ & 100 & & & & 100 & & & & 100 & & & \\
\hline $4 \mathrm{~g} / \mathrm{kg}$ & 100 & & & & 100 & & & & 100 & & & \\
\hline $8 \mathrm{~g} / \mathrm{kg}$ & 100 & & & & 100 & & & & 100 & & & \\
\hline $16 \mathrm{~g} / \mathrm{kg}$ & 100 & & & & 100 & & & & 100 & & & \\
\hline Control group & 100 & & & & 100 & & & & 95 & 5 & & \\
\hline Saline group & 95 & & 5 & & 95 & & 5 & & 100 & & & \\
\hline $2 \mathrm{~g} / \mathrm{kg}$ & 95 & 5 & & & 100 & & & & 100 & & & \\
\hline $4 \mathrm{~g} / \mathrm{kg}$ & 100 & & & & 100 & & & & 100 & & & \\
\hline $8 \mathrm{~g} / \mathrm{kg}$ & 100 & & & & 100 & & & & 100 & & & \\
\hline $16 \mathrm{~g} / \mathrm{kg}$ & 85 & 5 & 5 & 5 & 90 & 5 & 5 & & 85 & 10 & & 5 \\
\hline Control group & 95 & 5 & & & 95 & & 5 & & 95 & 5 & & \\
\hline Saline group & 90 & 10 & & & 100 & & & & 100 & & & \\
\hline $2 \mathrm{~g} / \mathrm{kg}$ & 95 & & & 5 & 100 & & & & 100 & & & \\
\hline $4 \mathrm{~g} / \mathrm{kg}$ & 90 & 5 & & 5 & 95 & 5 & & & 95 & 5 & & \\
\hline $8 \mathrm{~g} / \mathrm{kg}$ & 90 & & 10 & & 100 & & & & 95 & 5 & & \\
\hline $16 \mathrm{~g} / \mathrm{kg}$ & $80^{*}$ & 10 & 5 & 5 & 85 & 10 & 5 & & 100 & & & \\
\hline
\end{tabular}

${ }^{*} P<0.05$ significant difference from control

GLU glucose, WBC white blood cells, NIT nitrite, PRO protein, BLD occult blood, KET ketone, BIL bilirubin, URO urobilinogen, $V_{C}$ ascorbic acid

have a uniform diet without variation throughout the testing period.

Safety pharmacology is a pharmacological method used to study drugs given at the recommended treatment doses, or higher doses, which may exert harmful pharmacological effects or adverse drug reactions [25-27]. Safety pharmacology research can provide information for clinical research and safe drug use, and can be used for longterm toxicity testing as a reference for the design and development of new indications [28-30]. The present research, conducted according to safety pharmacology research technical guidelines for natural medicines, tested the effects of Jinqing granules on critical body functions, such as respiratory rate, heart rate, and central nervous system activities.

Because the central nervous system plays a vital role in the development of and the regulation of physiological behaviors, the rats' daily routine activities and the climbing pole test were used to detect effects of Jinqing granules on the central nervous system [31]. Treatment at all doses did not affect the animals' performance in these rudimentary tests. Although the possibility of subtle central nervous system effects was not excluded, the tests gave no evidence of gross damage.

Measurement of rats' heart rate also did not reveal an abnormal effect in the Jinqing-treated animals, which is

Table 6 Effect of subchronic administration of Jinqing granules on hematologic indices in rats $(n=20)$

\begin{tabular}{llllllll}
\hline Parameters & WBC $\left(\times 10^{9} / \mathrm{L}\right)$ & $\mathrm{RBC}\left(\times 10^{12} / \mathrm{L}\right)$ & $\mathrm{PLT}\left(\times 10^{9} / \mathrm{L}\right)$ & $\mathrm{HGB}(\mathrm{g} / \mathrm{L})$ & $\mathrm{LYM} \%\left(\times 10^{9} / \mathrm{L}\right)$ & $\mathrm{GRAN}\left(\times 10^{9} / \mathrm{L}\right)$ & $\mathrm{HCT} \%$ \\
\hline Control group & $7.82 \pm 1.12$ & $8.52 \pm 0.82$ & $1024.67 \pm 141.96$ & $159.80 \pm 8.56$ & $78.28 \pm 3.70$ & $1.71 \pm 0.40$ & $35.83 \pm 3.18$ \\
Saline group & $8.58 \pm 0.75$ & $9.14 \pm 0.88$ & $1313.29 \pm 105.33$ & $166.86 \pm 8.73$ & $80.75 \pm 4.43$ & $1.93 \pm 0.41$ & $36.01 \pm 2.22$ \\
$2 \mathrm{~g} / \mathrm{kg}$ & $7.59 \pm 1.54$ & $8.17 \pm 0.72$ & $1140.13 \pm 266.16$ & $157.87 \pm 14.27$ & $79.11 \pm 3.41$ & $1.89 \pm 0.28$ & $38.61 \pm 4.47$ \\
$4 \mathrm{~g} / \mathrm{kg}$ & $7.91 \pm 1.17$ & $8.56 \pm 2.04$ & $1105.07 \pm 115.30$ & $152.53 \pm 8.63$ & $81.75 \pm 0.96$ & $1.52 \pm 0.27$ & $37.59 \pm 3.75$ \\
$8 \mathrm{~g} / \mathrm{kg}$ & $7.93 \pm 1.94$ & $8.73 \pm 1.02$ & $1076.13 \pm 98.33$ & $155.67 \pm 7.89$ & $76.99 \pm 1.78$ & $1.57 \pm 0.46$ & $36.15 \pm 4.50$ \\
$16 \mathrm{~g} / \mathrm{kg}$ & $7.32 \pm 2.07$ & $9.19 \pm 0.49$ & $1297.10 \pm 86.70$ & $167.4 \pm 12.15$ & $82.07 \pm 2.97^{*}$ & $1.82 \pm 0.42$ & $38.96 \pm 1.48$ \\
\hline
\end{tabular}

Values represent mean \pm SD

WBC white blood cell, RBC red blood cell, PLT blood platelet, HGB hemoglobin, $L Y M$ lymphocytes, Gran neutrophils, $H C T$ red blood cell specific volume

${ }^{*} P<0.05$, significantly different from control values 
Table 7 Effect of subchronic administration of Jinqing granules on serum biochemistry measurements in rats $(n=20)$

\begin{tabular}{llllllllll}
\hline Parameters & $\mathrm{ALT}(\mathrm{U} / \mathrm{L})$ & $\mathrm{AST}(\mathrm{U} / \mathrm{L})$ & $\mathrm{TP}(\mathrm{g} / \mathrm{L})$ & $\mathrm{TG}(\mathrm{g} / \mathrm{L})$ & $\mathrm{GLU}(\mathrm{mmol} / \mathrm{L})$ & UREA(mmol/L) & $\mathrm{CREA}(\mathrm{mmol} / \mathrm{L})$ & $\mathrm{T}-\mathrm{Bil}(\mathrm{g} / \mathrm{L})$ & $\mathrm{ALB}(\mathrm{g} / \mathrm{L})$ \\
\hline Control group & $32.17 \pm 5.59$ & $105.58 \pm 31.84$ & $57.59 \pm 4.12$ & $0.34 \pm 0.17$ & $5.33 \pm 1.77$ & $5.64 \pm 1.18$ & $32.76 \pm 3.95$ & $2.32 \pm 0.43$ & $25.81 \pm 4.46$ \\
Saline group & $34.13 \pm 3.90$ & $111.45 \pm 22.26$ & $55.33 \pm 5.57$ & $0.43 \pm 0.15$ & $5.15 \pm 2.67$ & $5.51 \pm 1.36$ & $33.94 \pm 6.81$ & $2.36 \pm 0.33$ & $26.38 \pm 4.14$ \\
$2 \mathrm{~g} / \mathrm{kg}$ & $31.63 \pm 3.84$ & $119.03 \pm 31.76$ & $56.16 \pm 3.64$ & $0.32 \pm 0.08$ & $5.46 \pm 1.77$ & $5.66 \pm 0.88$ & $29.55 \pm 8.76$ & $2.87 \pm 0.27$ & $26.76 \pm 4.67$ \\
$4 \mathrm{~g} / \mathrm{kg}$ & $35.72 \pm 5.99$ & $119.78 \pm 15.37$ & $59.07 \pm 5.52$ & $0.33 \pm 0.21$ & $5.19 \pm 1.64$ & $5.46 \pm 0.96$ & $31.74 \pm 7.14$ & $2.44 \pm 0.41$ & $27.29 \pm 5.33$ \\
$8 \mathrm{~g} / \mathrm{kg}$ & $33.96 \pm 3.97$ & $125.76 \pm 20.33$ & $55.98 \pm 3.73$ & $0.34 \pm 0.07$ & $5.04 \pm 1.44$ & $6.02 \pm 0.66$ & $35.28 \pm 6.94$ & $3.15 \pm 0.35$ & $25.91 \pm 4.58$ \\
$16 \mathrm{~g} / \mathrm{kg}$ & $37.69 \pm 3.03$ & $137.63 \pm 26.44^{*}$ & $58.45 \pm 4.09$ & $0.45 \pm 0.09$ & $4.88 \pm 2.31$ & $6.23 \pm 1.07$ & $36.66 \pm 5.46$ & $3.43 \pm 0.42^{*}$ & $27.61 \pm 8.61$ \\
\hline
\end{tabular}

Values represent means $\pm S D$

ALT alanine aminotransferase, AST aspartate aminotransferase, TP total protein, TG triglycerides, GLU glucose, UREA blood urea nitrogen, CREA creatinine, TC total cholesterol, $A L B$ albumin

${ }^{*} P<0.05$, significantly difference from control values

some evidence that the drug may have no adverse effect on the cardiovascular system $[32,33]$.

The subchronic toxicity testing is used to assess the long-term safety of exogenous substances [34]. In our 30day clinical trial, two male and one female rats in Group VI died. Because autopsy of these animals disclosed signs of damage from improper oral lavage, and no other abnormalities were found at autopsy, we feel that toxic effects of Jinqing were not the cause of the deaths.

Changes in body weight can be used as indicators of general toxicity of drugs and chemicals [35-37]. In our study, Jinqing granules had only minimal effect on the rate of weight gain, and the effect was only statistically significant at the highest dose (Group VI; $16 \mathrm{~g} / \mathrm{kg}$ ) and not until 3 to 4 weeks of treatment. Whether this effect was due to effects of the medication is unknown.

Hematological analyses in humans and animals are a sensitive indicator of drug and chemical toxicity [38-40]. In analyses of blood indices, we found no abnormalities in several measurements in the Jinqing-treated animals (white blood cell count, red blood cell count, platelet count, hemoglobin, and neutrophil count), but a slight, statistically significant increase in lymphocyte counts (from 77 to $82 \times 10^{9} / \mathrm{ml}$ in Group IV animals) was found; we suspect this difference is of no clinical significance, because they were within normal physiological ranges [41-43].

As with other measurements, the biochemical tests revealed little abnormality in the Jinqing-treated animals, although aspartate aminotransferase and total bilirubin were modestly increased in Group VI animals. Aspartate aminotransferase is released into the blood [44], when liver-cell injury occurs, but an increase in serum aspartate aminotransferase value is not specific for liver disease [45]. Bilirubin is a breakdown product of normal heme catabolism [46]. With disease of the liver or biliary system, serum bilirubin values may rise [47], but increased values may be present in hematologic or other diseases as well. In our study, the combination of increased serum aspartate aminotransferase and total bilirubin raise the possibility of liver injury, but whether the mild abnormalities seen only with the highest doses of Jinqing are of clinical significance is unknown.

Table 8 Effect of subchronic administration of Jinqing granules on the organ coefficient $\left(\mathrm{g} / \mathrm{g}^{*} 100 \%\right)$ of male and female rats $(n=20)$

\begin{tabular}{|c|c|c|c|c|c|c|c|}
\hline Parameters & gender & Heart & Liver & Spleen & Lung & Kidney & Testis or Ovary \\
\hline \multirow[t]{2}{*}{ Control group } & Male & $0.35 \pm 0.01$ & $3.24 \pm .024$ & $0.30 \pm 0.04$ & $0.51 \pm 0.05$ & $0.79 \pm 0.06$ & $1.25 \pm 0.12$ \\
\hline & Female & $0.37 \pm 0.05$ & $3.26 \pm 0.19$ & $0.31 \pm 0.03$ & $0.47 \pm 0.02$ & $0.76 \pm 0.06$ & $0.05 \pm 0.01$ \\
\hline \multirow[t]{2}{*}{ saline group } & Male & $0.37 \pm 0.03$ & $3.36 \pm 0.10$ & $0.28 \pm 0.04$ & $0.53 \pm 0.05$ & $0.80 \pm 0.04$ & $1.27 \pm 0.10$ \\
\hline & Female & $0.39 \pm 0.03$ & $3.45 \pm 0.14$ & $0.29 \pm 0.03$ & $0.52 \pm 0.02$ & $0.77 \pm 0.05$ & $0.04 \pm 0.01$ \\
\hline \multirow[t]{2}{*}{$2 \mathrm{~g} / \mathrm{kg}$} & Male & $0.35 \pm 0.02$ & $3.37 \pm 0.19$ & $0.32 \pm 0.05$ & $0.54 \pm 0.06$ & $0.78 \pm 0.04$ & $1.24 \pm 0.14$ \\
\hline & Female & $0.37 \pm 0.04$ & $3.37 \pm 0.36$ & $0.27 \pm 0.06$ & $0.55 \pm 0.08$ & $0.81 \pm 0.11$ & $0.05 \pm 0.01$ \\
\hline \multirow[t]{2}{*}{$4 \mathrm{~g} / \mathrm{kg}$} & Male & $0.35 \pm 0.01$ & $3.39 \pm 0.24$ & $0.31 \pm 0.05$ & $0.52 \pm 0.04$ & $0.75 \pm 0.06$ & $1.21 \pm 0.10$ \\
\hline & Female & $0.36 \pm 0.02$ & $3.27 \pm 0.22$ & $0.31 \pm 0.07$ & $0.50 \pm 0.05$ & $0.79 \pm 0.04$ & $0.05 \pm 0.01$ \\
\hline \multirow[t]{2}{*}{$8 \mathrm{~g} / \mathrm{kg}$} & Male & $0.36 \pm 0.04$ & $3.44 \pm 0.24$ & $0.28 \pm 0.04$ & $0.54 \pm 0.05$ & $0.78 \pm 0.06$ & $1.28 \pm 0.11$ \\
\hline & Female & $0.35 \pm 0.02$ & $3.32 \pm 0.18$ & $0.30 \pm 0.03$ & $0.52 \pm 0.05$ & $0.76 \pm 0.02$ & $0.05 \pm 0.01$ \\
\hline \multirow[t]{2}{*}{$16 \mathrm{~g} / \mathrm{kg}$} & Male & $0.34 \pm 0.05$ & $3.49 \pm 0.37^{*}$ & $0.26 \pm 0.05$ & $0.54 \pm 0.13$ & $0.83 \pm 0.11$ & $1.41 \pm 0.13^{*}$ \\
\hline & Female & $0.36 \pm 0.03$ & $3.52 \pm 0.16^{*}$ & $0.26 \pm 0.05$ & $0.54 \pm 0.04$ & $0.80 \pm 0.06$ & $0.06 \pm 0.01$ \\
\hline
\end{tabular}




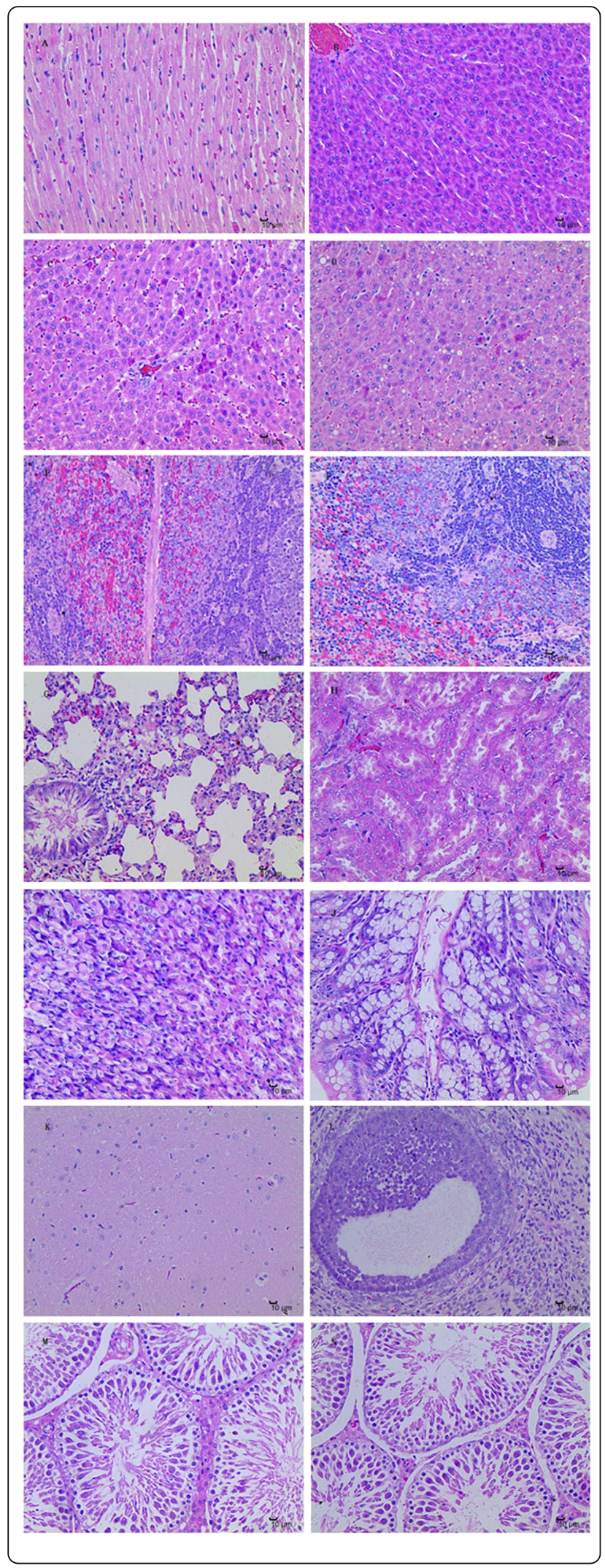

Fig. 5 H\&E staining of the liver, kidney, brain, heart, lung, spleen from the rats used in the subchronic toxicity test. $N=3$ per group, scale bar $=10 \mu \mathrm{m} ; 400 \times$. a Representative section of heart tissue (Group I- VI), with no histological abnormality. b Liver, 0 g/kg, Group I, without histological abnormality. c Liver, Group VI animals, with expansion of liver sinusoids, d Liver, Group VI animals, with various degrees of vacuolar degeneration in hepatocytes. e Spleen, $0 \mathrm{~g} / \mathrm{kg}$ (Group I), with no histological abnormality. f Spleen, Group VI rats, with decreased numbers of lymphocytes and increased numbers of macrophages. g Representative section of Lung, Group I-VI, with no histological abnormality. $\mathbf{h}$ Representative section of kidney, Group I-VI, with no histological abnormality. i Representative section of stomach, Group I-VI, with no histological abnormality. j Representative section of intestines, Group I-VI with not histological abnormality. $\mathbf{k}$ Representative section of brain, Group I-VI, with no histological abnormality. I Representative section of ovary, Group I- VI, with no histological abnormality. $\mathbf{m}$ Representative sections of testicle, Group I-V, with testicular tubules were arranged neatly and tightly. $\mathbf{n}$ Testicle, Group VI, with the number of sperm in seminiferous tubules appeared decreased

Serum creatinine is an important index of kidney function $[48,49]$, and blood urea nitrogen values can reflect glomerular filtration function [50]. That these tests were normal in our rats is evidence that Jinqing granules, even at high doses, did not adversely affect renal function. This conclusion is supported also by the normal urinary $\mathrm{pH}$, specific gravity, and protein values in treated animals.

Organ coefficient is an important index in the evaluation of new-drug preclinical toxicity and effect on target organs $[51,52]$. Studies have reported that the organ coefficient may be increased due to congestion, edema, hypertrophy, and other causes, and it may be decreased due to organ shrinking and degenerative changes [53, 54]. These effects may not be directly attributed to a direct effect of the drug being tested, and could be due a secondary change. In this study, no abnormalities in organ coefficient were found, except for slight but statistically significantly decreased values for the liver and testes at the $16 \mathrm{~g} / \mathrm{kg}$ dose.

After the 30-day trial, histological examination of the heart, liver, spleen, lung, kidney, stomach, intestines, brain, testes and ovary found minimal changes, except for decreased number of sperm in seminiferous tubules of Group VI animals. Therefore, an adverse effect of Jinqing on reproductive capability and hepatotoxicity have to be considered.

Brain is a crucial organ for regulating mental development, and promotes endocrine release of human $[55,56]$. The hippocampus and cortex play an absolutely essential role in learning and memory [57, 58]. Hypothalamus regulates a variety of functions, including sleep, body temperature, thirst and hunger. In this study, histopathological displayed a normal neuronal structure in the hippocampus, cortex and hypothalamus, without inflammatory infiltrate or hemorrhagic lesions. In addition, in 
the subchronic toxicity test the change of behavior was not observed. Tests have shown that Jinqing granules had no effect on rats' brain.

We acknowledge that our study has limitations. The most consequential may be the relatively short duration of Jinqing feeding; trials of longer-term administration of the medication are needed. Also, results of tests in Sprague-Dawley rats may not be applicable to other animal species or to humans. Finally, despite our extensive testing for adverse events associated with Jinqing feeding, the tests may not have been sufficiently sensitive or specific to detect all adverse events.

The doses of Jinquing granules we fed to rats are well above those usually used in the treatment or prevention of gastric ulcers. Thus, although our findings are not directly transferrable to porcine husbandry, they give some assurance about the safety of Jinqing feeding.

\section{Conclusions}

Extensive safety pharmacology and subchronic toxicity tests on rats fed ultra-high doses of Jinqing granules (up to $16 \mathrm{~g} / \mathrm{kg}$ ) revealed little evidence of toxicity on the animals' nervous, cardiovascular, respiratory, renal, and hematological systems. However, the highest dose was associated with slightly slowed weight growth and minor histologic changes of unknown significance, decreased numbers of sperm in seminiferous tubules, and increased values of serum aspartate aminotransferase and bilirubin. During the 30-day feeding test, 3 rats that received the $16 \mathrm{~g} / \mathrm{kg}$ dose died, but the deaths were most likely due to trauma of oral gavage, not drug toxicity. Jinqing granules given to Sprague-Dawley rats orally for 30 days at a dose of $8 \mathrm{~g} / \mathrm{kg}$ or less appears safe, but higher doses were not proven safe. The significance of these observations with respect to usage of Jinqing in animals, or possibly in humans, deserves thorough investigation.

\section{Acknowledgments}

This work was supported in part by a grant (2013NZ0019) from the Science and Technology Department of Sichuan Province, China. We thank the College of Veterinary Medicine, Sichuan Agricultural University, Cheng du 611130, China, for kindly providing facilities.

\section{Funding}

Supported in part by a grant (2013NZ0019) from Science \& Technology Department of Sichuan Province, China.

\begin{abstract}
Availability of data and materials
The datasets supporting the findings is contained within the manuscript. Please note that not all of the original data is available during the manuscript is accepted for publication. This is because multiple researchers have completed the research project, and the information required is not accessible. However, if further raw data are desired, additional data sets are used and / or in the current research analysis, which can be reasonably requested from the corresponding author.
\end{abstract}

\section{Authors' contributions}

$X R$ and QR carried out most of the experiments and drafted the manuscript. $Y L, G Y, L Z, F S$ and $C L$ critically revised the experiment design and manuscript.
$M X, Y L, Q D, Y L, Q J, H L, X Y$ and $K S$ helped with the experiment. All authors read and approved the final manuscript.

\section{Competing interests}

The authors declare that they have no competing interests.

\section{Consent for publication \\ Not applicable.}

\section{Ethics approval}

All experimental procedures involving animals were approved by Sichuan Agricultural University Animal Care and Use Committee (registration No. SCAU2016061801).Based on the principles of the International Committee on Laboratory Animals, the rats were separated equally according to gender and maintained at $20-25{ }^{\circ} \mathrm{C}$ and relative humidity of $55 \pm 5 \%$. Artificial lighting was adjusted to $12 \mathrm{~h}$ of light (from 08:00 to 20:00) and $12 \mathrm{~h}$ of darkness from 20:00 to 08:00. The rats were allowed to drink water freely, and they acclimated for 7 days before experiments were begun.

\section{Publisher's Note}

Springer Nature remains neutral with regard to jurisdictional claims in published maps and institutional affiliations.

Received: 18 February 2017 Accepted: 5 June 2017

Published online: 17 June 2017

\section{References}

1. Lin YH, Chen KK, Chiu JH. Coprescription of Chinese herbal medicine and western medications among prostate cancer patients: a population-based study in Taiwan. Evid Based Complement Alternat Med. 2012;1:147015.

2. Wang $P$, Zhou HL, Xue FZ, et al. Pattern recognition for traditional Chinese medicine nature of 60 kinds of herbal medicine based on high performance capillary electrophoresis fingerprint. J Chin Med Mat. 2013;36(9):1419-24.

3. Zhang XW, Jia HL. Origin and development of umbilical therapy in traditional Chinese medicine. Chinese Acupuncture \& Moxibustion. 2014;34(6):607.

4. Parveen A, Parveen B, Parveen R. Challenges and guidelines for clinical trial of herbal drugs. J Pharm Bioallied Sci. 2015;7(4):329.

5. Ntie-Kang F, Onguéné PA, Lifongo LL, et al. The potential of anti-malarial compounds derived from African medicinal plants, part II: a pharmacological evaluation of non-alkaloids and non-terpenoids. Malar J. 2014;13(1):81

6. Lai JN, Tang JL, Wang JD. Observational studies on evaluating the safety and adverse effects of traditional chinese medicine. Evid Based Complement Alternat Med. 2013;2013(18):697893.

7. CA Smith, Ros Priest et al. The ethics of traditional chinese and western herbal medicine research: views of researchers and human ethics committees in Australia. Evid Based Complement Alternat Med. 2011 (1741-427X):256915. Article ID 256915. doi:10.1155/2011/256915.

8. Chinese Pharmacopoeia Committee. Pharmacopoeia of the People's Republic of China. Beijing: Chinese medical science and technology press; 2015. p. 217.

9. Yan SK, Lin ZY, Dai WX, et al. Chemometrics-based approach to modeling quantitative composition-activity relationships for Radix Tinosporae. Interdiscip Sci. 2010;2(3):221-7.

10. Khan MA, Gray Al, Waterman PG. Tinosporaside, an 18-norclerodane glucoside from Tinospora cordifolia. Phytochemistry. 1989;28(1):273-5.

11. Wei $L$, Kazuo K, Lijuan L, et al. New lignan glucosides from the stems of Tinospora sinensis. Chem Pharm Bull. 2004;52(5):638-40.

12. Qin NB, Wang AL, Li DH, et al. Cytotoxic clerodane furanoditerpenoids from the root of Tinospora sagittata. Phytochem Lett. 2015;12:173-6.

13. He C. Canarium album (Lour.) Raeusch.(Qingguo, Chinese Olive). Diet Chin Herbs. 2015;5(17):307-13.

14. Rong $Q, L i Y L, X u M$, et al. A formulation for the treatment of gastric ulcer drugs and its preparation method. Chin, CN 105287732 A, 2016-2-03.

15. Rong $\mathrm{Q}, \mathrm{Xu} \mathrm{M}, \mathrm{Dong} \mathrm{Q}$, et al. In vitro and in vivo bactericidal activity of Tinospora sagittata (Oliv.) Gagnep. var. craveniana (S.Y.Hu) Lo and its main effective component Palmatine against Helicobacter pylori from pig. BMC Complement Altern Med. 2016;16(1):331.

16. Swaby H, Gregory NG. A note on the frequency of gastric ulcers detected during post-modem examination at a pig abattoir. Meat Sci. 2012;90:269-71. 
17. China Institute of Veterinary Drugs Control, 2011. Test no.1596: safety pharmacology research technical guidelines of veterinary medicine, natural medicine.

18. Duan $\mathrm{WL}$, Liang X. Technical guidelines assembly of veterinary medicine research. Beijing: Chemical Industry Press; 2011.

19. Pugsley MK, Authier S, Curtis MJ, et al. Principles of safety pharmacology. $\mathrm{Br}$ J Pharmacol. 2008;154(7):1382-99.

20. Lindgren S, Bass A, BriscoeBenchmarking R K, et al. safety pharmacology regulatory packages and best practice. J Pharmacol Toxicol Methods. 2008; 58(2):99-109.

21. Xiang F, Yin ZQ, Jia RY, et al. Acute and subchronic toxicity as well as evaluation of safety pharmacology of Galla chinensis solution. J Ethnopharmacol. 2014;162:181-90

22. OECD. Guideline for testing of chemicals: repeated dose 28-day oral toxicity in rodents. Test no. 407, adopted in 1981, and revised method adopted 3 October 2008. Paris: OECD; 2008a

23. Yan L, Gao H, Sun JJ. Research on body weight and reference value of main organ of wistar rats. Pract Prev Med. 2009;16(6):1708-11.

24. Ihongbe JC, Salisu AA, Bankole JK. A study on the effect of Mondia White on organ and body weight of wistar rats. Int J Herbs Pharmacol Res. 2012; 1(1):18-23.

25. Shi L, Lv YP, Qian BC. Discussion on basic request and standardization in safety pharmacology. Chin J Clin Pharmac Ther. 2005:10:961-5.

26. Guth BD, Siegl PKS. Safety pharmacology assessment. Pharm Med. 2007; 21(5):357-61.

27. JM Korth-Bradley, et al. Pharmacokinetics and safety of a single intravenous dose of the antibiotic tigecycline in patients with cirrhosis. J Clin Pharmacol. 2010;51(1): 93-101.

28. Mandhane DSN, Ayer UB, Midha AS. Preclinical efficacy and safety pharmacology of SUN-1334H, a potent orally active antihistamine agent. Drugs in R \& D. 2008;9(2):93-112.

29. Huang FH. General pharmacology study of new drug of TCM technical requirement and the analysis of common problems. J Tradit Chin Med. 2007;32:82-4.

30. Broichhausen $C$, Riquelme $P$, Ahrens $N$, et al. In question: the scientific value of preclinical safety pharmacology and toxicology studies with cell-based therapies. Mol Ther Methods Clin Dev. 2014;1(1):14026.

31. Zaciraglc A, Nakas-icindic E, Hadzovic A, Avdagic N. Average values of electrocardiograph parameters in healthy, adult Wistar rats. Med Arh. 2004; 58:268-70.

32. Bonilha AMM, Saraiva RM, Kanashiro RM, Portes LA, Antonio EL, Tucci PJF. A routine electrocardiogram cannot be used to determine the size of myocardial infarction in the rat. Braz J Med Biol Res. 2005;38:615-9.

33. Pratt DS, Kaplan MM. Evaluation of abnormal liver-enzyme results in asymptomatic patients. N Engl J Med. 2000;342:1266-71.

34. Aniagu SO, Nwinyi FC, Akumka DD, et al. Toxicity studies in rats fed nature cure bitters. Afr J Biotechnol. 2005:4:72-8.

35. Raza M, Al-Shabanah OA, El-Hadiyah TM, et al. Effect of prolonged vigabatrin treatment on hematological and biochemical parameters in plasma, liver and kidney of Swiss albino mice. Sci Pharm. 2002;70:135-45.

36. Tan PV, Mezui C, Enow-Orock G, et al. Teratogenic effects, acute and sub chronic toxicity of the leaf aqueous extract of ocimum suave Wild (Lamiaceae) in rats. J. Ethnopharmacol. 2008;115:232-7.

37. Teo S, Stirling D, Thomas S, et al. A 90-day oral gavage toxicity study of Dmethylphenidate and D, L-methylphenidate in Spraque-Dawley rats. Toxicology. 2002;179:183-96

38. Adeneye AA, Ajagbonna OP, Adeleke TI, et al. Preliminary toxicity and phytochemical studies of the stem bark aqueous extract of Musanga cecropioides in rats. J Ethno Pharmacol. 2006;105:374-9.

39. Liju VB, Jeena K, Kuttan R. Acute and subchronic toxicity as well as mutagenic evaluation of essential oil from turmeric (Curcuma longa). Food Chem Toxicol. 2013:53:52-61.

40. Rahman ME, Siddiqui MK, Jamil K. Effects of vepacide (Azadirachta indica) on aspartate and alanine aminotransferase profiles in a subchronic study with rats. Hum Exp Toxicol. 2001;20:243-9.

41. Alemán $\mathrm{CL}$, Más RM, Rodeiro I, et al. Reference database of the main physiological parameters in Sprague-Dawley rats from 6 to 32 months. Lab Anim. 1998:32:457-66.

42. Petterino C, Argentino-Storino A. Clinical chemistry and haematology historical data in control Sprague-Dawley rats from pre-clinical toxicity studies. Exp Toxicol Pathol. 2006;57:213-9.
43. Han ZZ, Xu HD, Kim KH, et al. Reference data of the main physiological parameters in control Sprague-Dawley rats from pre-clinical toxicity studies. Lab Anim Res. 2010;26:153-64.

44. Han YD, Song SY, Lee JH, Lee DS, Yoon HC. Multienzyme-modified biosensing surface for the electrochemical analysis of aspartate transaminase and alanine transaminase in human plasma. Anal Bioanal Chem. 2011:400:797-805.

45. Ozer J, Ratner M, Shaw M, Bailey W, Schomaker S. The current state of serum biomarkers of hepatotoxicity. Toxicology. 2008;245:194-205.

46. Vitek $\mathrm{L}$. The role of bilirubin in diabetes, metabolic syndrome, and cardiovascular diseases. Front Pharmacol. 2012;3:55.

47. Green RM, Flamm S. AGA technical review on the evaluation of liver chemistry tests. Gastroenterology. 2002;123:1367-84.

48. Remuzzi G, Bertani T. Pathophysiology of progressive nephropathies. N Eng Jed. 1998;339:1448-56

49. Lameire N, Van Biesen W, Vanholder R. Acute renal failure. Lancet. 2005;365: 417-30

50. Wang SL. Veterinary clinical diagnostics (third edition). Beijing: China Agriculture; 2006.

51. Yuan BL. The significance and shortcoming of organ or body weight ratio used in drug safety evaluation. Chin New Drug J. 2003;12:960-3.

52. Gu LJ, Yang XH, Chen QJ, Sun JX, Xiao Y, Le JY, et al. Study on the normal reference values of organs' weight and organ/body coefficients in SD rats. J Labour Med. 2005;22:453-4.

53. Wei J, Wu XG, Lin $H$. A further observation on the serum biochemical values of chickens infected with Eimeriatenella or E. acervulina and the discussion on the pathological lesions. Chin J Prev Vet Med. 2002:32:25-7.

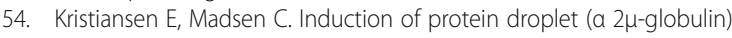
nephropathy in male rats after short-term dosage with 1, 8-cineole and Ilimonene. Toxicol Lett. 1995;80:147-52.

55. Biran J, Tahor M, Wircer E, Levkowitz G. Role of developmental factors in hypothalamic function. Front Neuroanat. 2015;9(7):47.

56. Machluf Y, Gutnick A, Levkowitz G. Development of the zebrafish hypothalamus. Ann N Y Acad Sci. 2011:1220(1):93-105.

57. O'Reilly RC, Rudy JW. Conjunctive representations in learning and memory: principles of cortical and hippocampal function. Psychol Rev. 2001;108(2): 311-45.

58. Witter MP, Naber PA, Haeften T, et al. Cortico-hippocampal communication by way of parallel parahippocampal-subicular pathways. Hippocampus. 2000:10(4):398-410.

\section{Submit your next manuscript to BioMed Central and we will help you at every step:}

- We accept pre-submission inquiries

- Our selector tool helps you to find the most relevant journal

- We provide round the clock customer support

- Convenient online submission

- Thorough peer review

- Inclusion in PubMed and all major indexing services

- Maximum visibility for your research

Submit your manuscript at www.biomedcentral.com/submit 